\title{
No-fat diet for treatment of donor site chyle leakage in vascularized supraclavicular lymph node transfer
}

\author{
Ik Hyun Seong, \\ Jin-Woo Park, \\ Kyong-Je Woo \\ Department of Plastic and \\ Reconstructive Surgery, Ewha Womans \\ University Mokdong Hospital, Ewha \\ Womans University College of \\ Medicine, Seoul, Korea
}

\begin{abstract}
Supraclavicular lymph node (SCLN) flap is a common donor site for vascularized lymph node transfer for the treatment of lymphedema. Chyle leakage is a rare but serious complication after harvesting SCLN flap in the neck. We report a case of chyle leakage at the SCLN donor site and its successful management. A 52-year-old woman underwent SCLN transfer for treatment of lower extremity lymphedema. After starting a regular diet and wheelchair ambulation on the 3rd postoperative day, the amount of drainage at the donor site increased (8-62 $\mathrm{mL} /$ day) with the color becoming milky, which suggested a chyle leak. Despite starting a low-fat diet on the 4th postoperative day, the chyle leakage persisted $(70 \mathrm{~mL} /$ day). The patient was started on fat-free diet on the 5th postoperative day. The amount of drainage started to decrease and the drain color became more clear within 24 hours. The drainage amount remained less than $10 \mathrm{~mL} /$ day from the 8th postoperative day, and we removed the drain on the 12th postoperative day. There was no seroma or other wound complications at follow-up 4 weeks after the operation. The current case demonstrates that a fat-free diet can be a first-line treatment for low output chyle leakage after a SCLN flap.
\end{abstract}

Keywords: Chyle / Free tissue flaps / Lymph nodes / Lymphedema

\section{INTRODUCTION}

With the development of lymphatic microsurgery, treatment of lymphedema is evolving into a physiologic procedure. Physiologic treatment can be divided into lymphaticovenular anastomosis (LVA) and vascularized lymph node transfer (VLNT). It is known that the mechanism behind VLNT involves the transferred lymph node draining lymphatic fluid from the interstitium to the lymph node, which in turn, drains into the pedicle vein [1]. VLNT shows promising and beneficial results in patients with both early and advanced lymphedema [2]. Submental, groin, axilla, supraclavicular, and intra-abdominal lymph

Correspondence: Kyong-Je Woo

Department of Plastic and Reconstructive Surgery, Ewha Womans University

Mokdong Hospital, Ewha Womans University College of Medicine,

1071 Anyangcheon-ro, Yangcheon-gu, Seoul 07985, Korea

E-mail: economywoo@gmail.com

Received August 12, 2020 / Revised August 27, 2020 / Accepted November 27, 2020 nodes can be used as VLNT donor site. There is a potential risk of donor site lymphedema when using groin and axilla lymph nodes [3], and visible scars can remain on the submandibular area when the submental lymph node is used. The use of supraclavicular lymph node (SCLN) has risk of damaging critical surrounding structures, but there is no risk of facial nerve injury, scars can be hidden, and donor site lymphedema is rare [4]. However, the transverse cervical artery and vein have variable anatomy and are located relatively deep. Although it is rare, chyle leak can develop when the main thoracic lymphatic vessels are injured during dissection [5]. We report a case of donor site chyle leakage after supraclavicular lymph node transfer (SCLNT) and its successful management with a fat-free diet.

\section{CASE REPORT}

A 52-year old woman diagnosed with cervical cancer stage IB1 
had been treated with radical abdominal hysterectomy, bilateral salpingo-oophorectomy, bilateral pelvic lymph node dissection, para-aortic lymph node dissection, and chemotherapy. She had no history of hypertension, diabetes or surgery prior to this diagnosis. Five years after her treatment she complained of heat sensation and pain in both legs, for which she was diagnosed cellulitis. Further diagnostic work up was done and she received LVA for bilateral leg lymphedema. The frequency of cellulitis decreased but the symptoms and swelling persisted in the right leg. SCLNT to the right lower leg was planned because that was where lymphedema was most severe.

The right SCLN was harvested from the right neck of the patient. During flap harvesting, visible lymphatic vessels were carefully clipped with microclips, and there was no gross injury

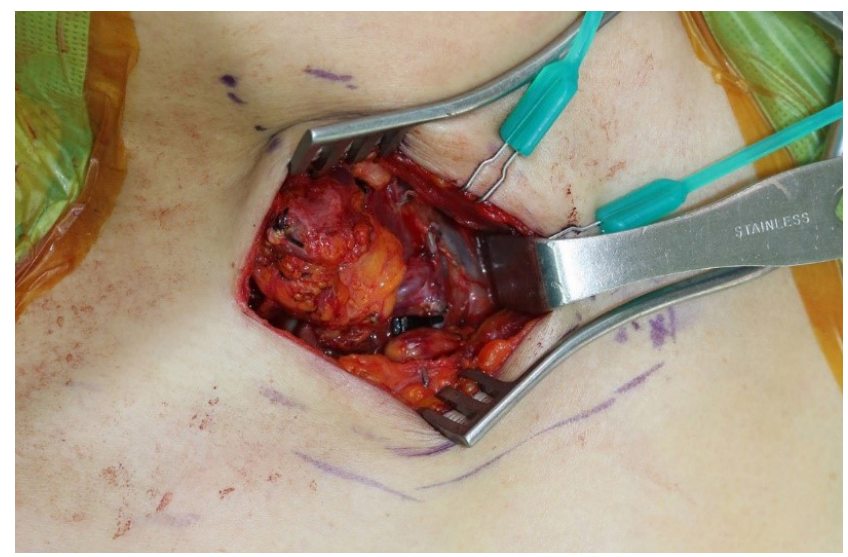

Fig. 1. Intraoperative photograph before division of the pedicle of the supraclavicular lymph node flap. inflicted to the main thoracic lymphatic vessels (Fig 1). A closed suction drain was inserted in the donor site, the platysma was closed with interrupted sutures using absorbable thread, and the skin was closed with simple interrupted sutures. For 48 hours postoperatively, oral intake was restricted. The drainage color was clear and the drainage amount was less than $10 \mathrm{~mL} /$ day for the first 2 postoperative days. A regular diet and wheelchair ambulation began on the 3rd day after surgery. On the 4th postoperative day, the amount of drainage started to increase (8-62 mL/day) with the drainage color becoming milky, suggesting chyle leakage (Fig 2). A low-fat diet was started on the 4th postoperative day, but the chyle leakage continued without a decrease in the amount of drainage $(70 \mathrm{~mL} /$ day). A fat-free diet was started on the 5 th postoperative day. Within 24 hours of starting fat-free diet, the drainage amount started to decrease and the color became clear (Fig 3). The drainage amount remained less than $10 \mathrm{~mL} /$ day from the 8 th postoperative day, and the drain was removed on the 12th postoperative day. No seroma or wound complications was found at 4 weeks postoperative follow-up.

\section{DISCUSSION}

Chyle leakage can occur when there is an injury to the paraaortic lymphatic system or the chylous system between the abdomen and lower neck. It commonly occurs after head and neck surgery, mostly on the left side, but about $25 \%$ is known to occur on the right side [6]. Most chyle leakage in the neck area occurs after lymph node dissection during head and neck sur-
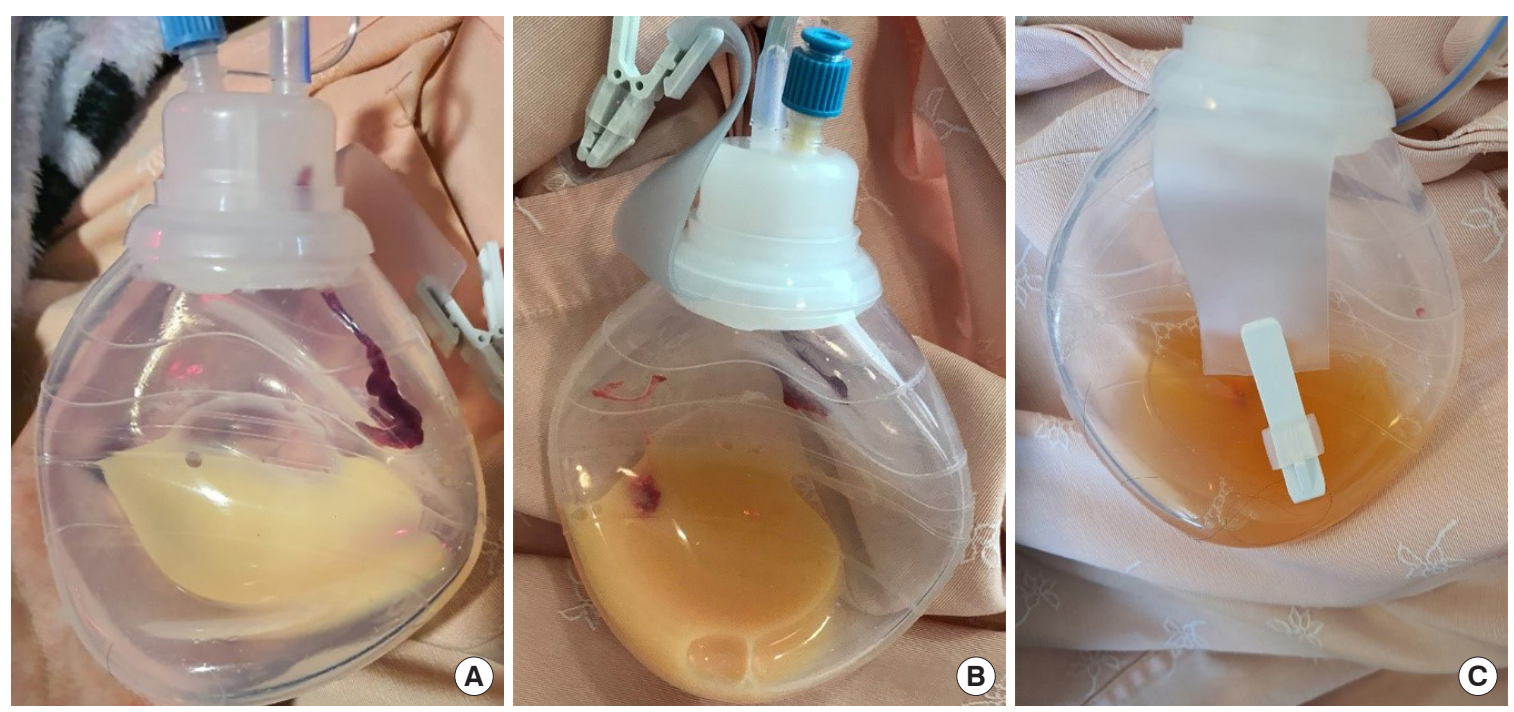

Fig. 2. Changes in drainage color following chyle leakage from supraclavicular donor site. (A) Drainage color became milky on the 4th day after surgery, suggesting a chyle leak. (B) Drainage color on the 5th day after surgery. The drainage color was not changed 24 hours after starting a low-fat diet. (C) Drainage color on the 6th day after surgery. The drainage color was clear 24 hours after starting a fat-free diet. 


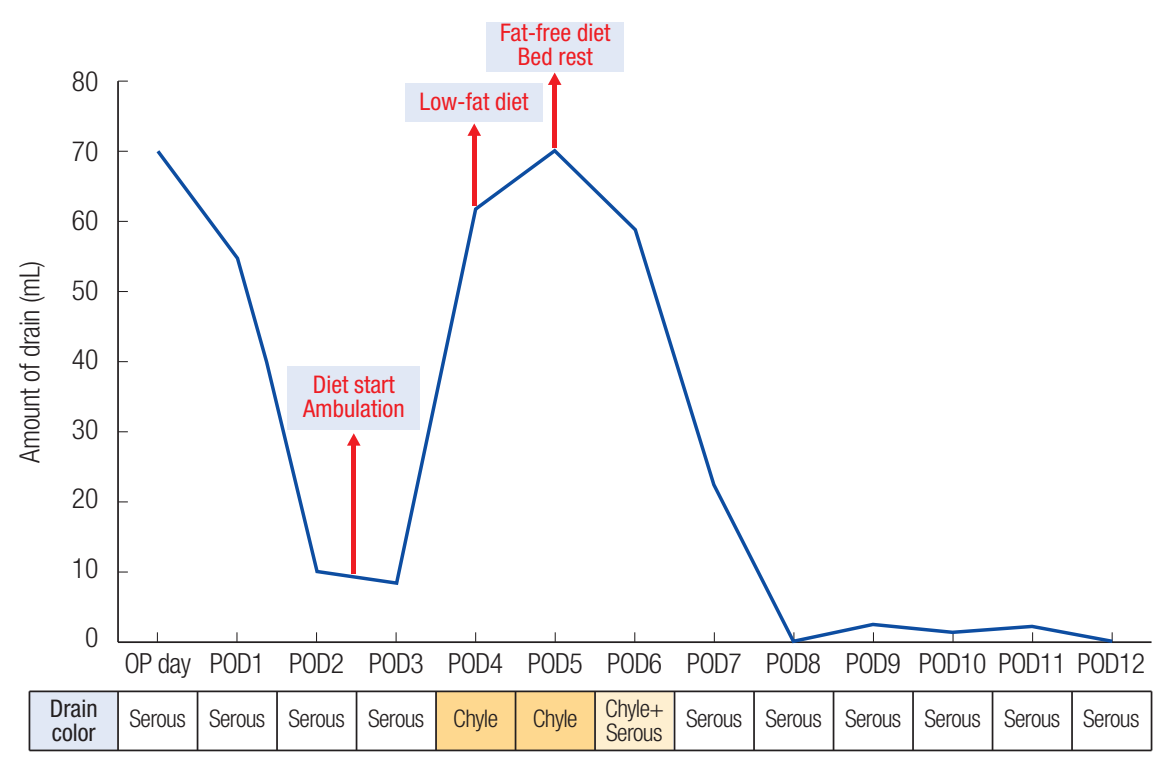

Fig. 3. Changes in drainage amount and color according to postoperative day. The amount of drainage increased (8-62 $\mathrm{mL} /$ day) with the color becoming milky from the 4 th postoperative day. A fat-free diet and restriction of ambulation started on the 5th postoperative day. Drainage amount started to decrease with the color becoming clear within 24 hours. The drainage amount remained less than $10 \mathrm{~mL} /$ day from the 8 th postoperative day, and the drain was removed on the 12th postoperative day before discharge. OP day, operative day; POD, postoperative day.

gery. The use of SCLN for VLNT has been increased, but there has been no consensus regarding treatment of donor chyle leakage after SCLN harvest.

If there is chyle leak, it can lead to delayed wound healing, dehydration, malnutrition, electrolyte disturbance, and immunosuppression [7]. If the amount of drainage per day is less than $500 \mathrm{~mL}$, it is classified as low output leakage, and if it is over 500 $\mathrm{mL}$ per day, it is classified as high output leakage. Various treatment options have been reported for chyle leakage. Treatments include radiologic intervention and surgical intervention, while non-operative treatments include limiting oral intake, restricting fat consumption, providing parenteral nutrition, diuresis, and medications to decrease alimentary tract secretion [7]. Those various treatment options suggest that there has been no consensus regarding treatment of chyle leakage in the neck.

Surgical intervention is often proposed to treat high output chyle leakage, and in some cases, thoracic duct embolization may be necessary $[8,9]$. However, due to the anatomical variation of the thoracic duct, surgical ligation or embolization is not always effective $[10,11]$. There was one case report of high output chyle leakage after SCLNT, which reported a failed surgical intervention to treat chyle leakage [12]. Surgical re-exploration was performed, and the injured lymphatic duct was ligated under the microscope, but chyle leak was not resolved [12]. In another case of high output chyle leakage, blood patch was used when chyle leakage was not resolved by conservative treatment or surgical treatment [13]. Although it was not chyle leakage, there was also a case report that cerebrospinal fluid leakage was resolved using an acellular dermal matrix [14].

In the current case, we demonstrate that low output chyle leakage can be managed successfully with a fat-free diet. Low output chyle leakage is thought to be caused by indirect flow leakage due to damage to lymph vessels other than the major thoracic lymph vessels. Methods to reduce the flow of chyle from the abdomen are low-fat diet, fat-free diet, and ambulation restriction. In this case, the authors found that a low-fat diet was not effective to treat low output chyle leak. With lowfat diet, no change in drain amount or color was observed over 24 hours. As soon as the fat-free diet started, however, the drain pattern began to change. The drainage amount began to decrease and the color became clear within 24 hours after the start of fat-free diet (Fig 3). Ambulation restriction may have been a compensatory factor by reducing chyle flow from reduced abdominal pressure. Other authors have suggested drain removal and aspiration to treat low output chylous fistula, but aspiration itself is cumbersome and has possible complications [15].

There is a significant anatomical variation of the thoracic lymphatic duct and the pedicle of the SCLN flap [11]. Especially because the pedicle originates from the deep and lower portion of the neck, delicate manipulation is needed to avoid thoracic duct injury. Lymphatic vessels need to be clipped meticulously. If there is an injury to the large thoracic duct, lympho-venous anastomosis to the nearby vein can be one option to prevent postoperative chyle leak or lymphocele [5]. Despite these preventive measures during lymph node harvest in the neck, risk of chyle leakage exists. 
The current case demonstrates that low output chyle leakage after SCLNT can be successfully treated with a fat-free diet without invasive interventions. A fat-free diet can be a first-line treatment for low output chyle leakage in SCLN flap.

\section{NOTES}

\section{Conflict of interest}

No potential conflict of interest relevant to this article was reported.

\section{Ethical approval}

The study was approved by the Institutional Review Board of Ewha Womans University Mokdong Hospital (IRB No. 202008-018) and performed in accordance with the principles of the Declaration of Helsinki. Written informed consent was obtained.

\section{Patient consent}

The patient provided written informed consent for the publication and the use of her images.

\section{ORCID}

Ik Hyun Seong https://orcid.org/0000-0003-0289-0222

Jin-Woo Park https://orcid.org/0000-0002-3411-8563

Kyong-Je Woo https://orcid.org/0000-0002-7349-6743

\section{REFERENCES}

1. Cheng MH, Huang JJ, Wu CW, Yang CY, Lin CY, Henry SL, et al. The mechanism of vascularized lymph node transfer for lymphedema: natural lymphaticovenous drainage. Plast Reconstr Surg 2014;133:192e-198e.

2. Scaglioni MF, Arvanitakis M, Chen YC, Giovanoli P, ChiaShen Yang J, Chang EI. Comprehensive review of vascularized lymph node transfers for lymphedema: outcomes and complications. Microsurgery 2018;38:222-9.

3. Pons G, Masia J, Loschi P, Nardulli ML, Duch J. A case of donor-site lymphoedema after lymph node-superficial circumflex iliac artery perforator flap transfer. J Plast Reconstr Aesthet
Surg 2014;67:119-23.

4. Maldonado AA, Chen R, Chang DW. The use of supraclavicular free flap with vascularized lymph node transfer for treatment of lymphedema: a prospective study of 100 consecutive cases. J Surg Oncol 2017;115:68-71.

5. Ooi AS, Chang DW. 5-step harvest of supraclavicular lymph nodes as vascularized free tissue transfer for treatment of lymphedema. J Surg Oncol 2017;115:63-7.

6. Delaney SW, Shi H, Shokrani A, Sinha UK. Management of chyle leak after head and neck surgery: review of current treatment strategies. Int J Otolaryngol 2017;2017:8362874.

7. Sriram K, Meguid RA, Meguid MM. Nutritional support in adults with chyle leaks. Nutrition 2016;32:281-6.

8. Lee YS, Nam KH, Chung WY, Chang HS, Park CS. Postoperative complications of thyroid cancer in a single center experience. J Korean Med Sci 2010;25:541-5.

9. Cope C, Kaiser LR. Management of unremitting chylothorax by percutaneous embolization and blockage of retroperitoneal lymphatic vessels in 42 patients. J Vasc Interv Radiol 2002;13: $1139-48$

10. Sesti J, Luker J, Decker J, Paul S. Modified blood patch used to treat a high output chyle leak after Mckeown esophagectomy. Ann Thorac Surg 2020;109:e401-2.

11. Johnson OW, Chick JF, Chauhan NR, Fairchild AH, Fan CM, Stecker MS, et al. The thoracic duct: clinical importance, anatomic variation, imaging, and embolization. Eur Radiol 2016; 26:2482-93.

12. Teven CM, Hunter CL, Chang DW. Management of high-output chyle leak after harvesting of vascularized supraclavicular lymph nodes. Plast Reconstr Surg 2019;143:1251-6.

13. Windhaber RA, Holbrook AG, Krysztopik RJ. Blood patch treatment of chylothorax following transthoracic oesophagogastrectomy: a novel technique to aid surgical management. Ann R Coll Surg Engl 2010;92:W10-1.

14. Lee H, Eom YS, Pyon JK. A method to prevent cerebrospinal fluid leakage: reinforcing acellular dermal matrix. Arch Craniofac Surg 2020;21:45-8.

15. Farkas N, Wong J, Monib S, Thomson S. A systematic review of chyle leaks and their management following axillary surgery. Eur J Surg Oncol 2020;46:931-42. 